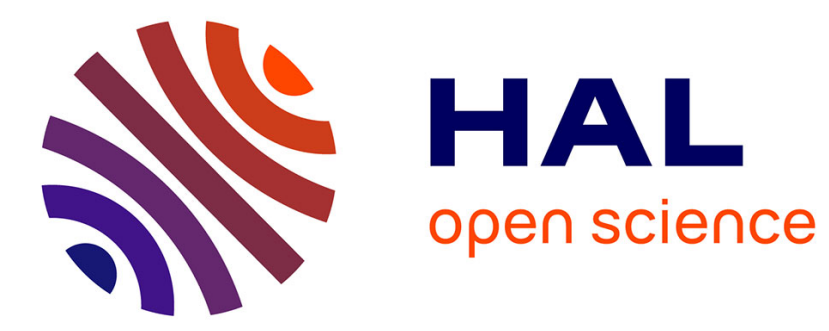

\title{
Experimental study of the phase transformation plasticity of 16MND5 low carbon steel under multiaxial loading
}

\author{
Michel Coret, Sylvain Calloch, Alain Combescure
}

\section{- To cite this version:}

Michel Coret, Sylvain Calloch, Alain Combescure. Experimental study of the phase transformation plasticity of 16MND5 low carbon steel under multiaxial loading. International Journal of Plasticity, 2002, 18 (12), pp.1707-1727. 10.1016/S0749-6419(01)00067-5 . hal-01006856

\section{HAL Id: hal-01006856 \\ https://hal.science/hal-01006856}

Submitted on 3 Jul 2017

HAL is a multi-disciplinary open access archive for the deposit and dissemination of scientific research documents, whether they are published or not. The documents may come from teaching and research institutions in France or abroad, or from public or private research centers.
L'archive ouverte pluridisciplinaire HAL, est destinée au dépôt et à la diffusion de documents scientifiques de niveau recherche, publiés ou non, émanant des établissements d'enseignement et de recherche français ou étrangers, des laboratoires publics ou privés. 


\title{
Experimental study of the phase transformation plasticity of 16MND5 low carbon steel under multiaxial loading
}

\author{
M. Coret,S. Calloch,A. Combescure \\ LMT-Cachan, E.N.S. Cachan/C.N.R.S. UMR 8535/Universite' Paris \\ 6, 61, Avenue du Président Wilson, 94235 Cachan Cedex, France
}

This paper is concerned with the experimental behaviour of a 16MND5 steel (french vessel steel) under complex loading. A particular attention is paid to plasticity induced by phase transformation. We present an experimental set-up to apply thermo-mechanical loads under tension-torsion. This apparatus enables us to reach temperature of $1200{ }^{\circ} \mathrm{C}$ at a maximum heating rate of $60^{\circ} \mathrm{C} \mathrm{s}^{-1}$ and a high cooling rate of $-30{ }^{\circ} \mathrm{C} \mathrm{s}^{-1}$. A series of tests is performed in order to show the rule of loading on transformation plasticity.

Keywords: A. Phase transformation; A. Thermomechanical processes; B. Constitutive behaviour; B. Metallic materials; C. Mechanical testing

\section{Introduction}

During welding or heat-treatment operations or even during catastrophic scenarios conceivable, for example, on civilian nuclear facilities, steel parts are subject to large thermal and mechanical actions leading to complex, multiaxial local loads (Inoue and Wang, 1985). In these situations, the steel materials employed undergo phase transformations under stress. Reliable numerical simulation of such processes and catastrophic situations requires the use of sophisticated models which take into consideration, on the one hand, the thermal, mechanical and metallurgical (phase change) behavior of these steels and, on the other hand, the coupling effects among 
these various physical phenomena. Indeed, interactions do exist among thermics, mechanics and metallurgy. These are illustrated in Fig. 1. The work we are presenting is part of a continuing study (Martinez, 1999) of the thermal, metallurgical and mechanical characterization of 16MND5 low carbon steel. In the previous works, coupling between thermics and mechanics, on the one hand, and thermics and metallurgy, on the other, was studied and modelled precisely (Martinez, 1999). In this study, we will focus more particularly on the influence of metallurgy on mechanics. Let us recall that if a mechanical loading is applied during the phase change there is a resulting residual strain called transformation plasticity. Two interpretations of the underlying physical mechanisms have been given by Greenwood and Johnson (1965) and by Magee (1966). According to Greenwood and Johnson, the residual strain comes from microplastic effects developed during the transformation as a consequence of the difference in phase compactness. In the case of martensitic transformations, Magee interprets transformation plasticity as the result of a propitious orientation of the platelets during the transformation. Since then, numerous experimental studies have been performed (Abrassart, 1972; Desalos, 1981; Denis et al., 1987; Hamata et al., 1991; Taleb et al., 2000; Martinez, 1999), leading to a variety of models (Greenwood and Johnson, 1965; Inoue and Wang, 1985; Leblond et al., 1989; Hamata et al., 1991; Cherkaoui and Berveiller, 2000; Fischer et al., 2000). All the models proposed are based on experimental observations under uniaxial loading. However, a recent study (Videau et al., 1996) shows that transformation plasticity is influenced by the multiaxial character of the mechanical loading. Therefore, the main objectives of the work reported here are, on the one hand, to develop an experimental apparatus on a current tension-torsion testing machine devoted to the study of transformation plasticity and, on the other hand, to present some experimental results to expand the experimental data base of multiaxial load cases.

The paper has three parts. In the first, we describe the experimental facility and quantify the performance it is likely to achieve. Particular attention is given to the determination of the temperature field on the tubular test specimen as well as to the

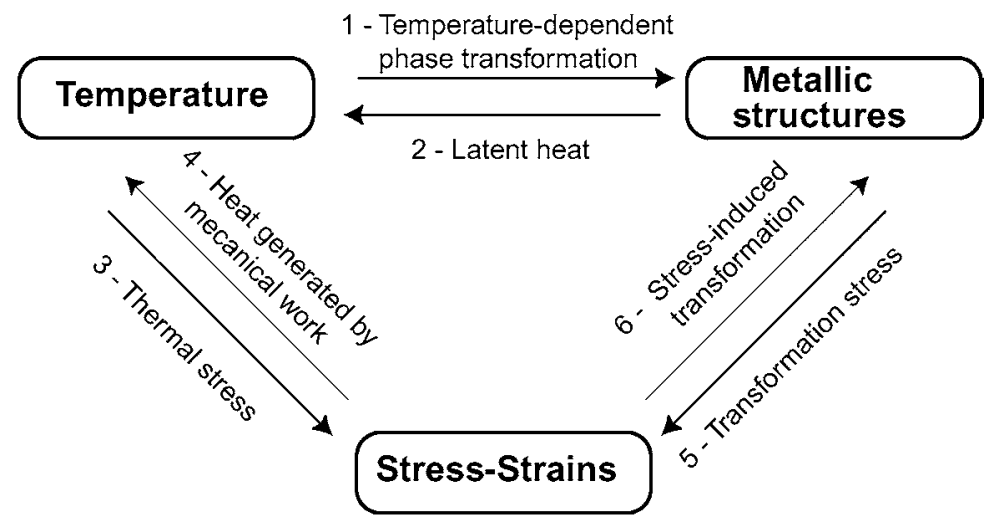

Fig. 1. Illustration of the various coupling among mechanics, thermics and metallurgy (Inoue and Wang, 1985). 
range of cooling and heating rates which can be obtained with the apparatus developed. In the second part, the results of three different tests on bainitic transformation are described and reported. Finally, the last part is dedicated to the interpretation of the test results.

\section{Experimental apparatus}

\subsection{Material and test specimen}

The material studied is the French 16MND5 vessel steel whose composition is given in Table 1. This is a low-alloy, low-carbon steel. Like all low carbon steels, it can undergo a variety of transformations depending on the cooling rate (Fig. 2). We will see that all the specimen are heated at $900{ }^{\circ} \mathrm{C}$ during $30 \mathrm{~s}$. Hence the CCT diagram presented in Fig. 2 is not directly applicable, but similar to our material's one. Bainitic transformation, obtained for a cooling rate on the order of $-3{ }^{\circ} \mathrm{C} \mathrm{s}^{-1}$, begins at $600{ }^{\circ} \mathrm{C}$, whereas martensitic transformation begins at $400{ }^{\circ} \mathrm{C}$ for a cooling rate greater than $-30^{\circ} \mathrm{C} \mathrm{s}^{-1}$. The material studied comes from a tank knockout and has a tempered bainitic structure.

The tension-torsion test specimen (Fig. 3) is a thin tube connected to two massive heads by a wide fillet. The central part, a tubular cylinder, enables us to obtain a quasi-homogeneous stress field of the following form:

$$
\underline{\underline{\sigma}}=\left[\begin{array}{ccc}
0 & 0 & 0 \\
0 & 0 & \tau \\
0 & \tau & 0
\end{array}\right]_{\left(\vec{e}_{r}, \vec{e}_{\theta}, \vec{e}_{z}\right)} \quad \underline{\underline{\varepsilon}}=\left[\begin{array}{lll}
\varepsilon_{r r} & 0 & 0 \\
0 & \varepsilon_{\theta \theta} & \frac{\gamma_{\theta z}}{2} \\
0 & \frac{\gamma_{\theta z}}{2} & \varepsilon_{z z}
\end{array}\right]_{\left(\vec{e}_{r}, \vec{e}_{\theta}, \vec{e}_{z}\right)}
$$

The axial and shear stresses are calculated respectively from the tension force $F$ and the torsion torque $C$ :

$$
\begin{aligned}
& \sigma=\frac{F}{S} \quad \text { with } \quad S=\frac{\pi}{4}\left(\phi_{\mathrm{ext}}^{2}-\phi_{\text {int }}^{2}\right) \\
& \tau=\frac{C}{\frac{I_{0}}{r_{\text {moy }}}} \quad \text { with } \quad I_{0}=\frac{\pi}{32}\left(\phi_{\mathrm{ext}}^{4}-\phi_{\text {int }}^{4}\right) \quad \text { and } \quad r_{\text {moy }}=\frac{\left(\phi_{\mathrm{ext}}+\phi_{\text {int }}\right)}{4}
\end{aligned}
$$

In order to simplify the notations, we will write: $\varepsilon=\varepsilon_{z z}$ and $\gamma=\gamma_{\theta z}$. We note that the geometry is dimensioned in such a way that a maximum equivalent stress of 1300

Table 1

Chemical composition of $16 \mathrm{MND} 5$ in mass $\%$

\begin{tabular}{lllllllllll}
\hline $\mathrm{C}$ & $\mathrm{S}$ & $\mathrm{P}$ & $\mathrm{Si}$ & $\mathrm{Mn}$ & $\mathrm{Ni}$ & $\mathrm{Cr}$ & $\mathrm{Mo}$ & $\mathrm{Cu}$ & $\mathrm{Co}$ & $\mathrm{Fe}$ \\
\hline 0.16 & 0.007 & 0.010 & 0.015 & 1.30 & 0.74 & 0.18 & 0.48 & 0.06 & 0.01 & Balance
\end{tabular}




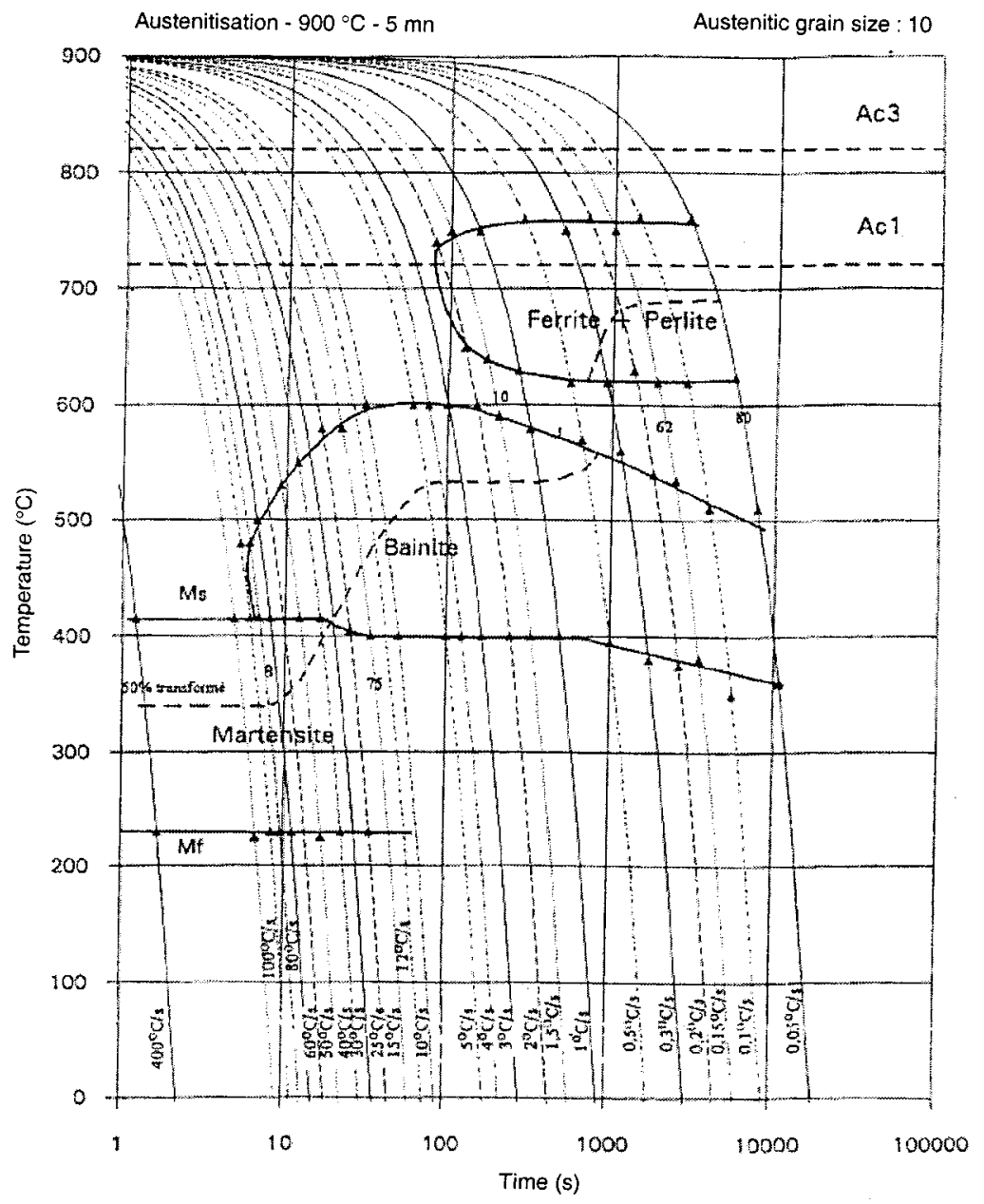

Fig. 2. TRC diagram of 16MND5 steel (Martinez, 1999).

MPa can be reached with the available test machine. (The yield stress of the martensitic 16MND5 steel is $1200 \mathrm{MPa}$.) Finally, we note that we have little material at our disposal and, therefore, we had to friction weld the central 16MND5 part to two E36 low carbon steel heads. Welding was followed by machining, curing and stress relieving phases.

\subsection{Experimental device}

The tests are performed on a MTS TTC servo-electro-hydraulic tension-torsion machine with maximum capacity of $100 \mathrm{kN}$ axial force and $1.2 \mathrm{kNm}$ torque.

Heating is provided by electromagnetic induction. Power is supplied by an $18 \mathrm{~kW}$ Celes generator driven by a Eurotherme $900 \mathrm{HP}$ regulator. This method allows fast 


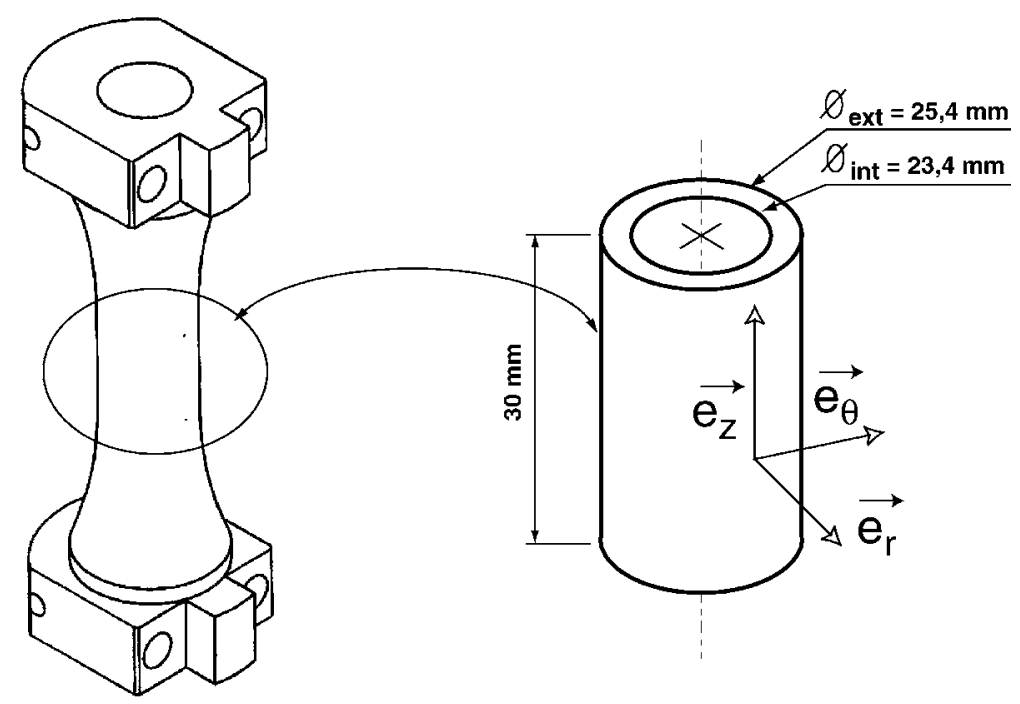

Fig. 3. Biaxial test piece and geometry of the central area.

heating rates and requires no electrical insulation of the test specimen. On the other hand, the temperature field greatly depends on the geometry of the inductor. For this reason, a tuning phase was necessary in order to obtain a homogeneous temperature field in the central part of the test specimen. The section view in Fig. 4 shows the disposition of the inductor facing the test specimen. Beside, a graph shows qualitatively the variation of the temperature field with respect to the altitude $z$. The axisymmetrical property of the temperature field depends, on the one hand, on the correct positioning of the inductor and, on the other hand, on its loops being exactly circular. Furthermore, the temperature gradient through the thickness is very small because in the frequency range of interest the skin thickness is on the order of 0,5 mm (Applications de l'électricité, 1982). Finally, water runs through the test specimen heads, which ensures constant temperature boundary conditions regardless of the heating time scale. The reader interested in induction heating of tension-torsion test specimens may refer to the work by Ellis and Bartolotta (1997). In their case, the device does not allow high cooling rates.

Cooling is achieved by injecting argon inside the test specimen. The gas enters through the lower wedge brace, sweeps over the wall of the test specimen to cool it and escapes through the upper wedge brace (Fig. 5). In order to optimize the argon flow along the walls, we placed a $\phi 20 \mathrm{~mm}$ external diameter alumina tube inside the test specimen. Thus, the gas is channelled between the inside of the test specimen and the outside of the alumina tube.

One last problem to avoid is decarburization and oxidation of the material which occurs very quickly at high temperature. Therefore, a two-part enclosure is placed around the test specimen. This enclosure enables us to create a confined space into which argon is injected. This device minimizes the oxidation and decarburization phenomena on the 16MND5 material. 


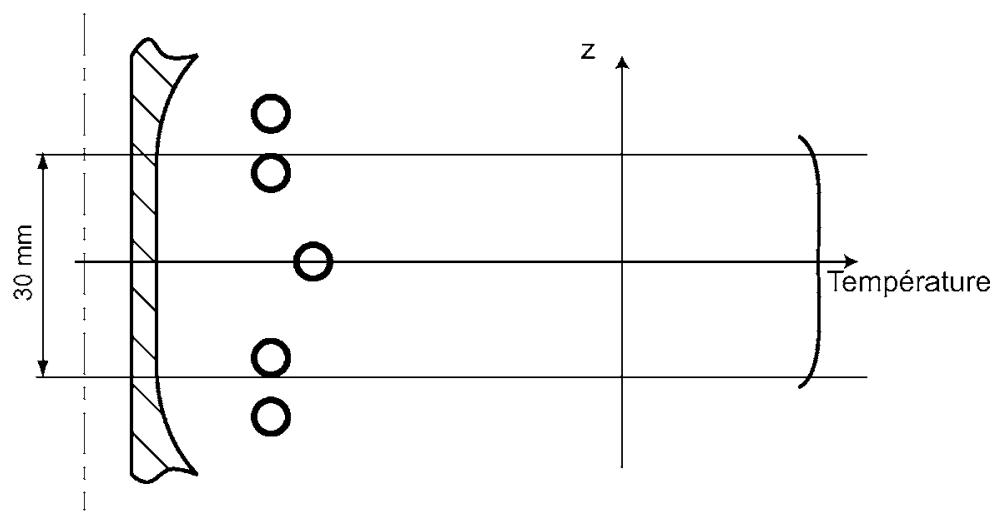

(a) Inductor profile and temperature profile

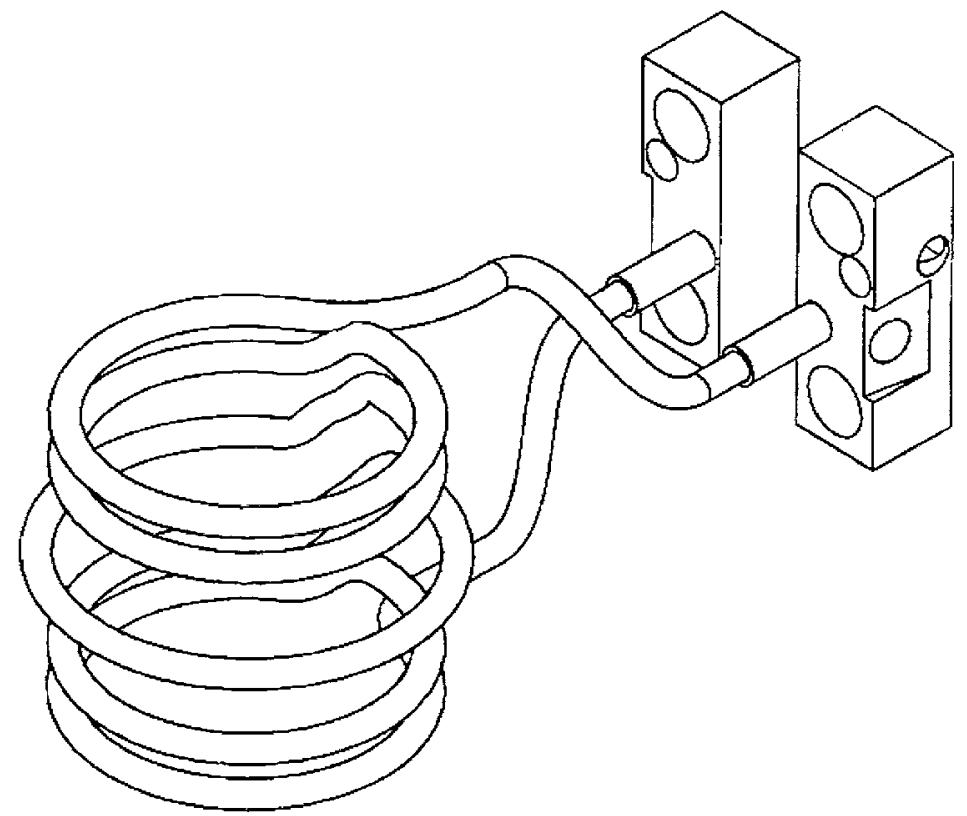

(b) Perspective view of the induction heater work coil

Fig. 4. Description of the inductor.

Heating and cooling tests were performed in order to study the temperature field. For this purpose, a test specimen was outfitted with twelve thermocouples (Fig. 6). We recorded the 12 temperature measurements during a heating test at $10^{\circ} \mathrm{C} \mathrm{s}^{-1}$ followed by cooling at $-3{ }^{\circ} \mathrm{C} \mathrm{s}^{-1}$. We note that the homogeneity of the temperature 


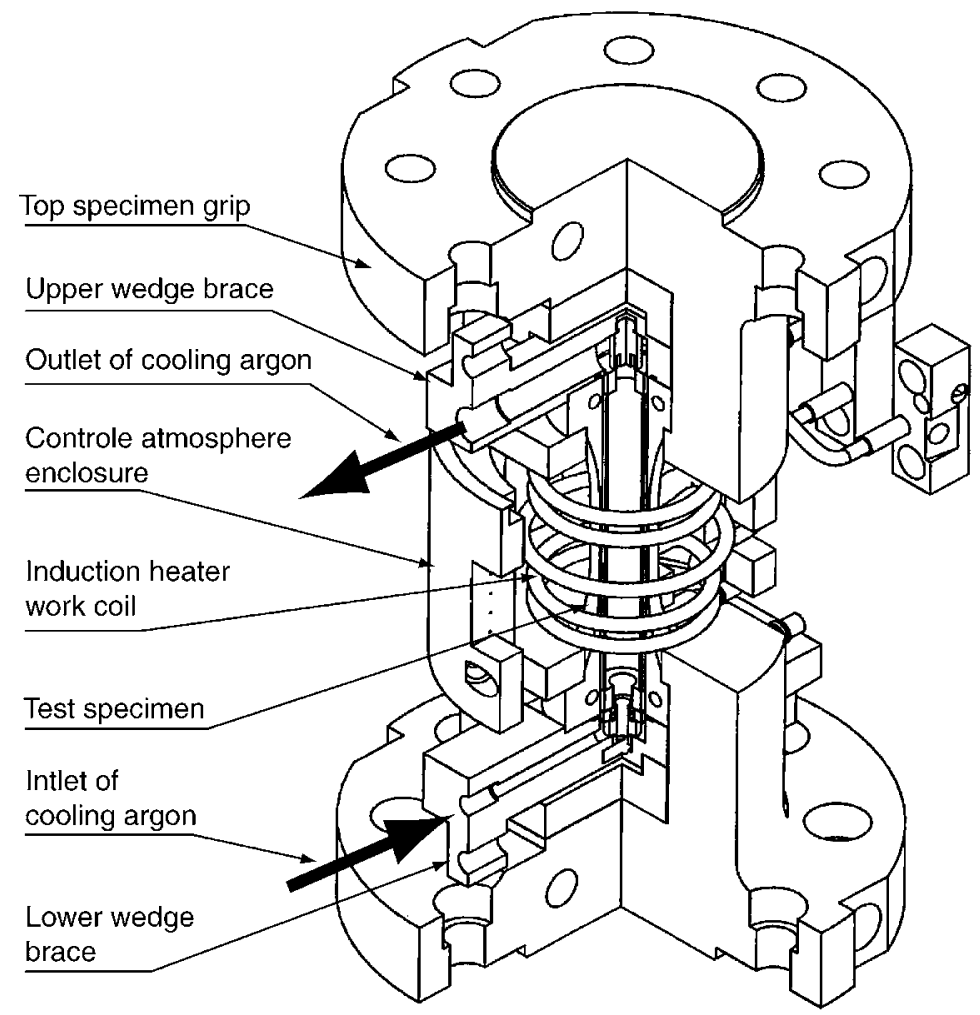

Fig. 5. Section view of the experimental device.

field is good (Fig. 7). That is to say, the maximum temperature deviation over the useful height of the test specimen is $\pm 10{ }^{\circ} \mathrm{C}$. We also note that the heating and cooling rates are respected. The minor breaks of slope occur during the phase changes. This can be explained by the fact that the austenitic transformation is endothermic, whereas ferritic transformations are exothermic. Furthermore, the austenitic phases are nonmagnetic. Therefore, the feedback control parameters should be adjusted during the test, which is always difficult.

This device provides a wide range of heating and cooling rates. Thus, various calibration tests (Fig. 8) showed that the heating rate may come close to $60{ }^{\circ} \mathrm{C} \mathrm{s}^{-1}$ and the cooling rate to $-30{ }^{\circ} \mathrm{C} \mathrm{s}^{-1}$. With such rates, one can expect to be able to reproduce all possible transformations: ferritic-pearlitic $\left(V \geqslant 0.5^{\circ} \mathrm{C} \mathrm{s}^{-1}\right)$, bainitic $(V$ $\left.\approx-3{ }^{\circ} \mathrm{C} \mathrm{s}^{-1}\right)$ and martensitic $\left(V-30{ }^{\circ} \mathrm{C} \mathrm{s}^{-1}\right)$. Fig. 9 shows a photograph of the device minus the enclosure.

\subsection{Measurements}

During the tests, the temperature is measured via twelve thermocouples welded in the useful zone (Fig. 6). The strains ( $\varepsilon$ and $\gamma$ ) are measured using a water-cooled 


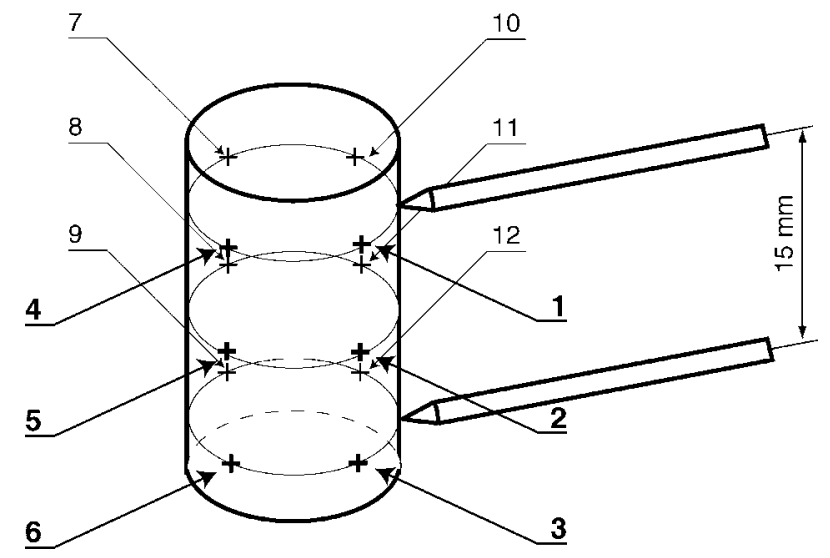

Fig. 6. Positioning of the thermocouples and extensometer on the useful part of the test piece.
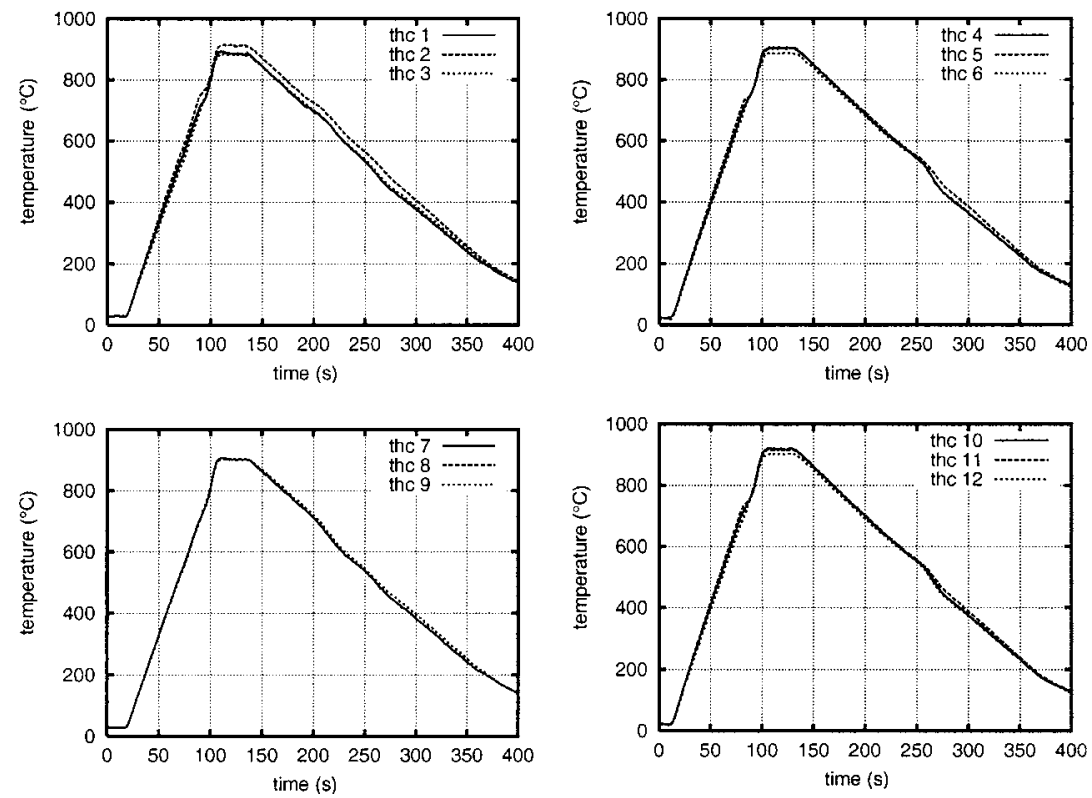

Fig. 7. Evolution of the temperature versus time for all thermocouples.

MTS 632.68F biaxial high temperature extensometer (Figs. 9 and 10). This extensometer was modified to reduce the distance between extension rods to $15 \mathrm{~mm}$. This modification, which can be applied to any type of extensometer, consists of using two skewed alumina rods. When the modified rods are used, the extensometer with its original springs is no longer in equilibrium on the test specimen. Therefore, we added a third spring to support the device (Fig. 10). Furthermore, we observed that due to the stiffnesses $k_{1}$ and $k_{2}$ of the springs the test specimen deforms at high 


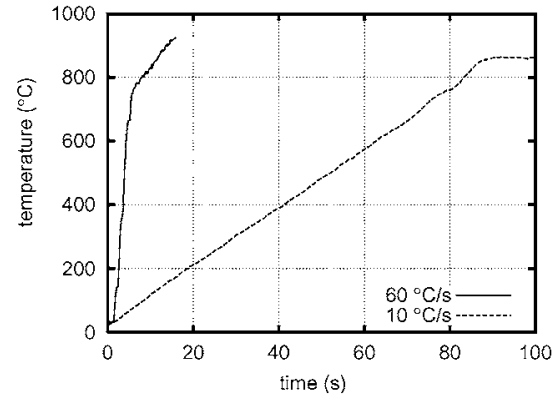

(a) Heating

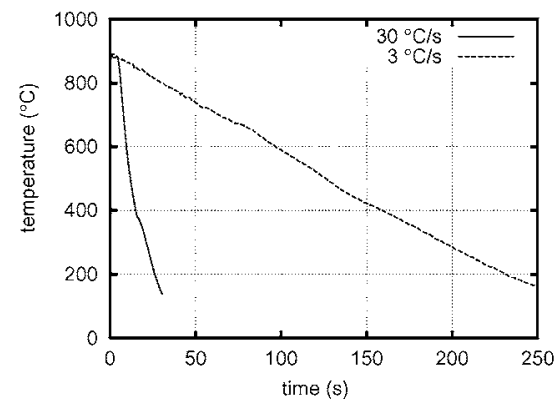

(b) Cooling

Fig. 8. Ranges of heating and cooling rates.

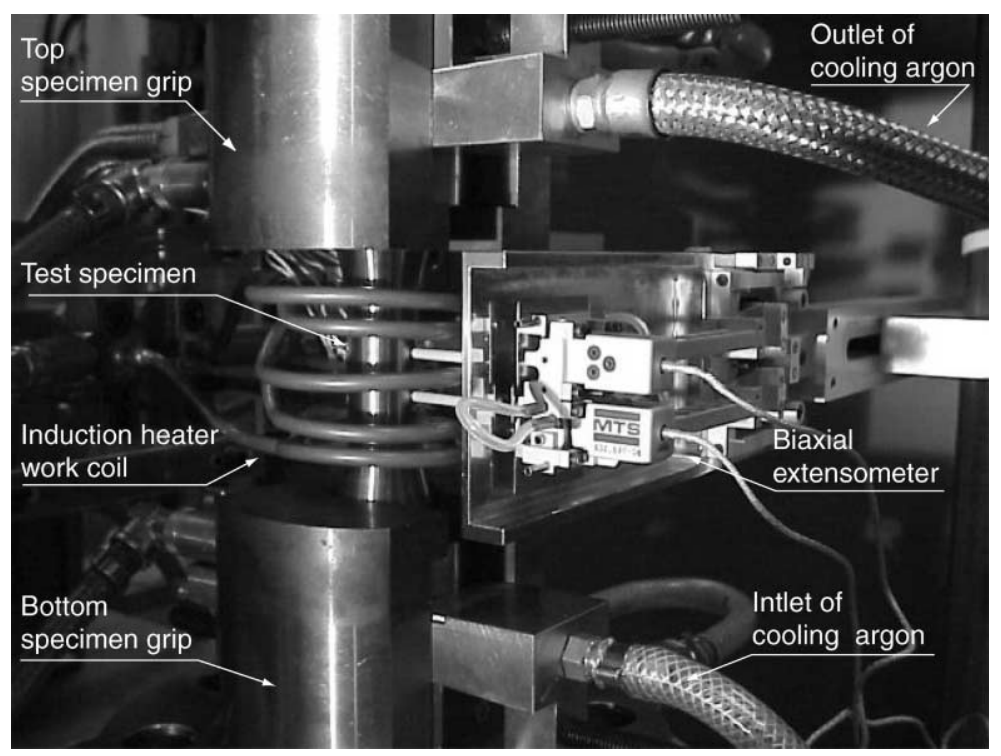

Fig. 9. Photograph of the experimental apparatus minus the controlled atmosphere enclosure.

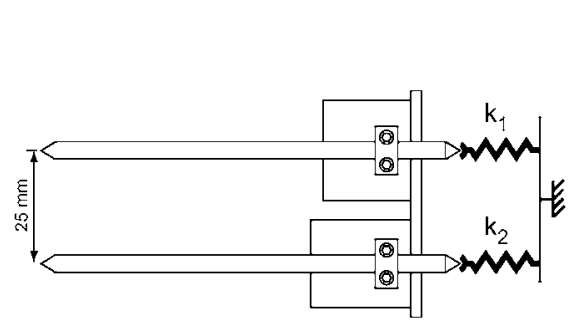

(a) Existing model

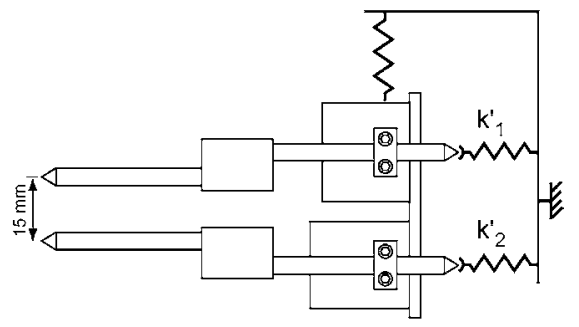

(b) Modified model

Fig. 10. Modification of the extension rods and retention springs of the biaxial extensometer. 


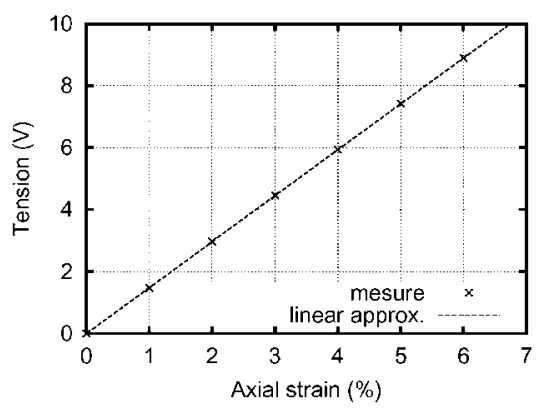

(a) Tension versus axial deformation

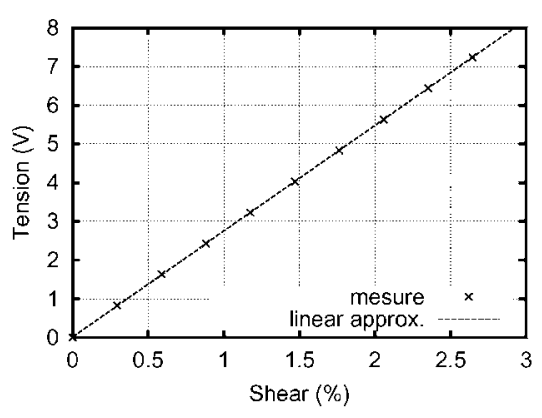

(b) Tension versus shear deformation

Fig. 11. Calibration curves of the biaxial extensometer.

temperature. The adjunction of the third spring enabled us to mount two springs with initial stiffnesses $k_{1}^{\prime}$ and $k_{2}^{\prime}$ less than $k_{1}$ and $k_{2}\left(k_{1}^{\prime}=\frac{k_{1}}{5}\right.$ and $\left.k_{2}^{\prime}=\frac{k_{2}}{5}\right)$. All these modifications ensure, on the one hand, the stability of the extensometer on the test specimen and, on the other hand, eliminate the problems caused by the deformation of the test specimen by the biaxial extensometer at high temperatures. We plotted the calibration curves in Fig. 11 and one can observe the good linearity of the device.

\section{Tests under uniaxial and multiaxial loading}

\subsection{Description of the loading paths}

The first tests concerned bainitic transformation. The onset of bainitic transformation is $600{ }^{\circ} \mathrm{C}$ and, at that temperature, the conventional yield stress $\sigma^{y}$ of bainite is $100 \mathrm{MPa}$ (Martinez, 1999). All the specimens were heated at a rate of $10{ }^{\circ} \mathrm{C} \mathrm{s}^{-1}$ and were maintained at a temperature of $900{ }^{\circ} \mathrm{C}$ for $30 \mathrm{~s}$, then cooled at a constant rate of $-3{ }^{\circ} \mathrm{C} \mathrm{s}^{-1}$. Three test specimens were used in this first series of tests. Each specimen was subjected to a succession of four thermomechanical load patterns as described in Fig. 12. The first loading was a free dilatometry test with heating rate $\dot{\theta}_{\text {chau }}=10^{\circ} \mathrm{C} \mathrm{s}^{-1}$ and cooling rate $\dot{\theta}_{\text {ref }}=-3{ }^{\circ} \mathrm{C} \mathrm{s}^{-1}$. The second loading was a dilatometry test under torque. Starting at the transformation temperature $\theta_{\text {trans }}$, a constant torque is applied to the test specimen during the cooling stage and released at the end. The third loading was a dilatometry test under axial force. In this case, starting at $\theta_{\text {trans }}$, an axial force was applied to the test specimen during the cooling stage and released at the end of the test. Finally, the fourth loading was a dilatometry test under combined tension-torsion load. Again beginning at $\theta_{\text {trans }}$, a torque and an axial force were applied to the test specimen simultaneously, then released at the end of cooling. We show in Fig. 12 the shape of the thermomechanical load curves and in Table 2 the values of the applied stresses in the different phases of the three tests. One can remark that for each phase, the two stress components $\sigma$ and $\tau$ are constant during phase transformation and that for each test, the von Mises 


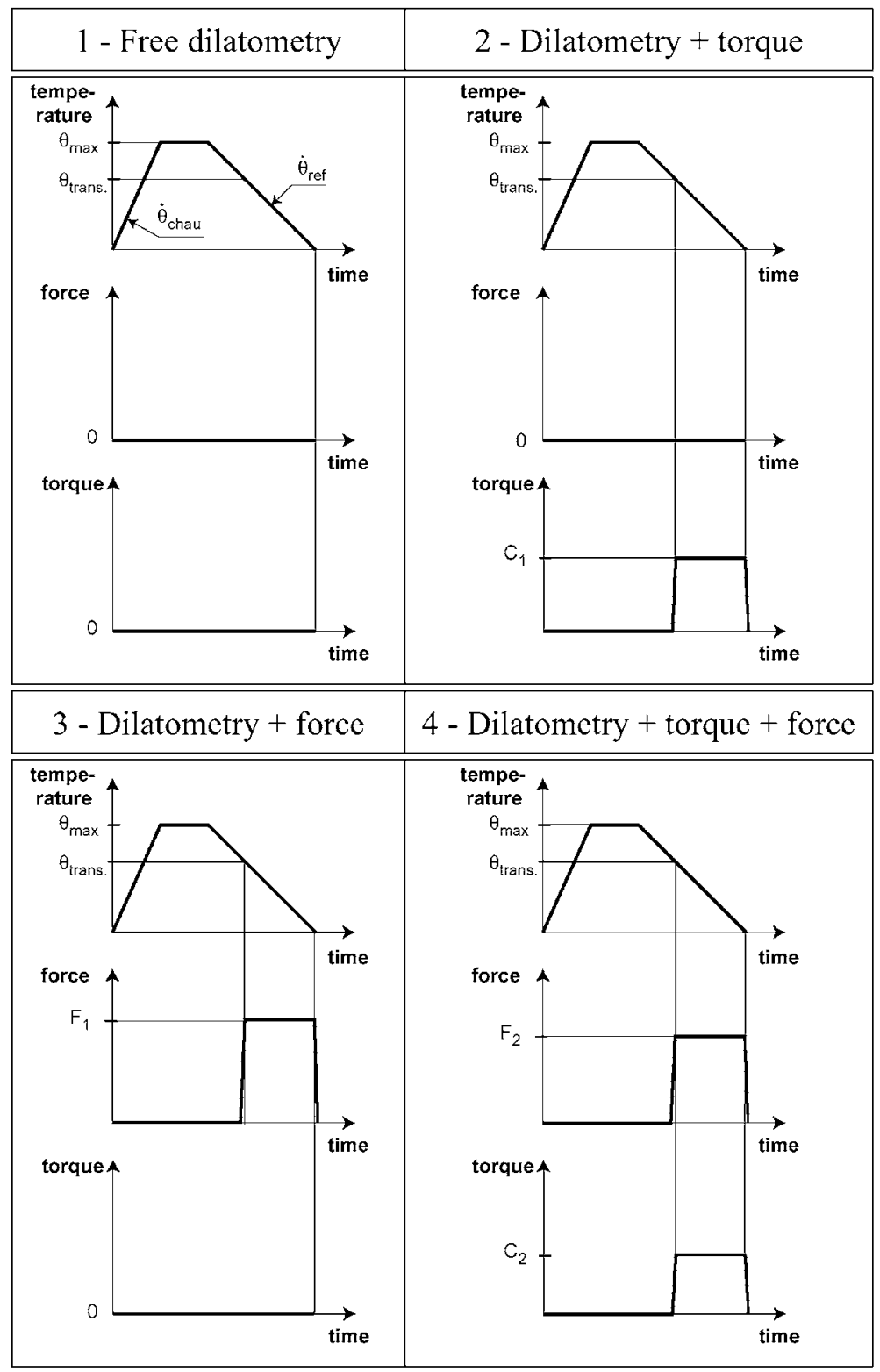

Fig. 12. Cycle of applied loads.

equivalent stress level $\left(\sigma_{\text {eq }}=\sqrt{\sigma^{2}+3 \tau^{2}}\right)$ is constant. This choice will be justified in part concerning the analysis of the experimental results.

Therefore, for each test, only one specimen was used. Thus, each specimen was subjected to four phases. We have decided to perform four experiments on each specimen because of the cost of one specimen. The hypothesis under this choice is 
Table 2

Stresses applied in the different phases of the three tests (MPa)

\begin{tabular}{|c|c|c|c|c|}
\hline Tests & Phase 1 & & Phase 2 & \\
\hline 1 & $\sigma=0$ & $\tau \sqrt{3}=0$ & $\sigma=0$ & $\tau \sqrt{3}=30$ \\
\hline 2 & $\sigma=0$ & $\tau \sqrt{3}=0$ & $\sigma=0$ & $\tau \sqrt{3}=45$ \\
\hline \multirow[t]{2}{*}{3} & $\sigma=0$ & $\tau \sqrt{3}=0$ & $\sigma=0$ & $\tau \sqrt{3}=60$ \\
\hline & Phase 3 & & Phase 4 & \\
\hline 1 & $\sigma=30$ & $\tau \sqrt{3}=0$ & $\sigma=21$ & $\tau \sqrt{3}=21$ \\
\hline 2 & $\sigma=45$ & $\tau \sqrt{3}=0$ & $\sigma=32$ & $\tau \sqrt{3}=32$ \\
\hline 3 & $\sigma=60$ & $\tau \sqrt{3}=0$ & $\sigma=42$ & $\tau \sqrt{3}=42$ \\
\hline
\end{tabular}

that the residual stress state is annealed by the austenitisation at $900{ }^{\circ} \mathrm{C}$. This will be checked in the full experimental program by doing the same experiments in the opposite order and shall be published soon. We have chosen to maintain specimen at maximum temperature of $900{ }^{\circ} \mathrm{C}$ during $30 \mathrm{~s}$ because we want to avoid to much austenitic grain size increase as well as carbon loss.

\subsection{Results on bainitic transformation}

The free dilatometry test enabled us to determine the thermomechanical characteristics of 16MND5, as shown in Fig. 13.

We obtained from the tests the following characteristics:

1. Coefficient of expansion of the ferritic phases $\left(T_{\text {ref }}=20{ }^{\circ} \mathrm{C}\right)$

$$
\begin{aligned}
& \alpha_{\alpha}=13,2.10^{-6}+8,5 \cdot 10^{-9} \cdot\left(T-T_{\text {ref }}\right){ }^{\circ} \mathrm{C}^{-1} \\
& \text { and } \overline{\alpha_{\left.\alpha\right|_{0}}^{700}}=16,1.10^{-6}{ }^{\circ} \mathrm{C}^{-1}
\end{aligned}
$$

2. Coefficient of expansion of austenitic phase $\left(T_{\text {ref }}=20^{\circ} \mathrm{C}\right)$

$$
\begin{aligned}
& \alpha_{\gamma}=41 \cdot 10^{-6}+2,3 \cdot 10^{-8} \cdot\left(T-T_{\text {ref }}\right){ }^{\circ} \mathrm{C}^{-1} \\
& \text { and } \overline{\alpha_{\left.\gamma\right|_{600} ^{1000}}}=22,6.10^{-6} \quad{ }^{\circ} \mathrm{C}^{-1}
\end{aligned}
$$

3. Compactness variation between phases at $20{ }^{\circ} \mathrm{C}$

$$
\Delta \varepsilon_{\alpha, \gamma}^{20^{\circ}}=-10,6.10^{-2}
$$

4. Characteristic temperatures of austenitic transformation

$$
\begin{aligned}
& \text { Initial : } A c_{1}=700{ }^{\circ} \mathrm{C} \\
& \text { Final : } A c_{3}=800{ }^{\circ} \mathrm{C}
\end{aligned}
$$




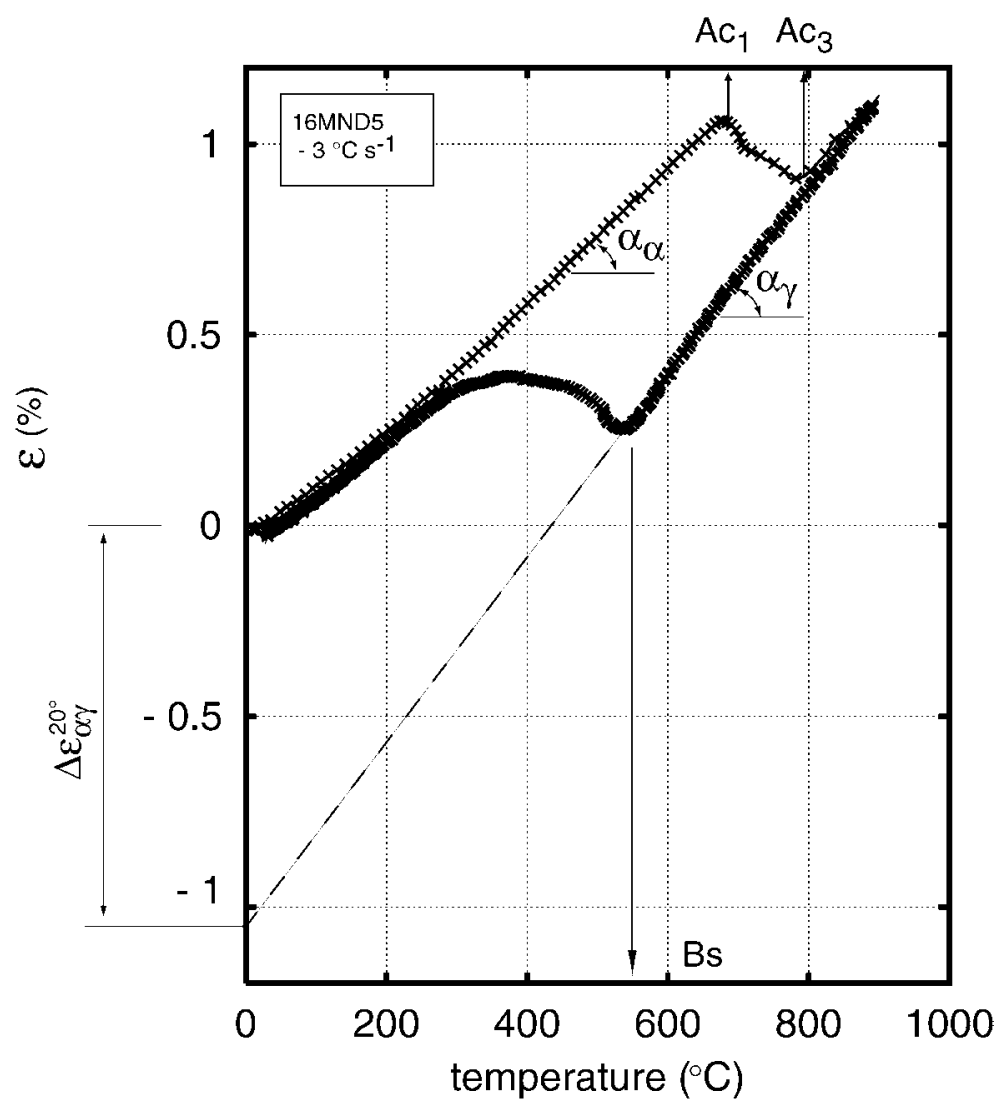

Fig. 13. Example of dilatation curve.

5. Characteristic temperatures of the bainitic transformation

$$
\text { Initial : } B s=560{ }^{\circ} \mathrm{C}
$$

In order to compare, we can cite (Taleb et al., 2000), these authors propose:

$$
\alpha_{\alpha}=15.10^{-6}{ }^{\circ} \mathrm{C}^{-1}, \quad \alpha_{\gamma}=23.5 \cdot 10^{-6}{ }^{\circ} \mathrm{C}^{-1} \text { and } \Delta \varepsilon_{\alpha, \gamma}^{20^{\circ}}=-0.01
$$

Figs. 14-16 show the axial and shear strains evolutions during the different phases of the three tests.

First we can observe that as soon as a mechanical loading is applied during the phase transformation, there is a residual strain measured at the end of the test. The residual strain is the result of the transformation plasticity. Qualitatively, we can see that a torque alone causes only a shear plastic strain (Phase 2 of Figs. 14-16), a force alone an axial strain (Phase 3 of Figs. 14-16) and a torque plus a force generate 

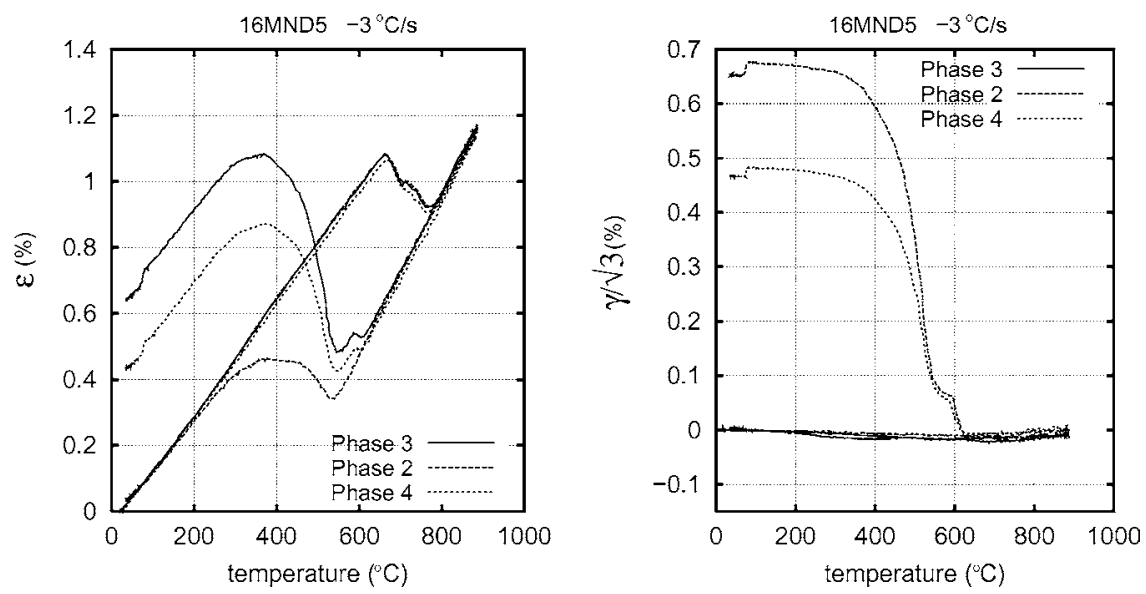

Fig. 14. Evolutions of total axial strain $\varepsilon$ and shear strain $\gamma$ during phases 2, 3 and 4 of test 3 .
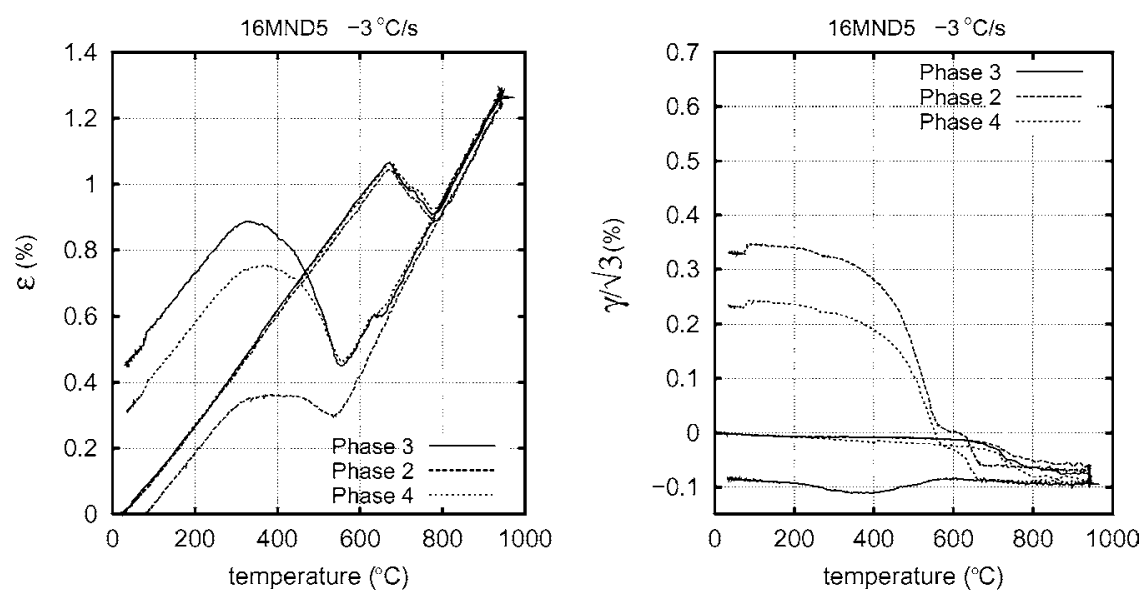

Fig. 15. Evolutions of total axial strain $\varepsilon$ and shear strain $\gamma$ during phases 2, 3 and 4 of test 2.

simultaneously axial and shear strains (Phase 4 of Figs. 14-16). However, we observe in Fig. 15 that during the third phase $(\sigma \neq 0$ and $\tau=0)$ a little shear strain is measured at the end of the phase. This shear strain appears during the austenitic transformation. This experimental default is probably due to either an heterogeneity of the temperature field or due to the presence of a residual stress field in the specimen. This phenomenon is little or none observed on the first specimen (Fig. 16) and on the third one (Fig. 14). Next, let us observe that the kinetics of the transformation is not affected by the mechanical loading, which can be easily deduced from the difference between the free dilatometry curve and the dilatometry curve under torque. This result is consistent with the works of Gautier et al. (1994), who observed no noticeable differences in the case of small applied loads. We also note that the shear 

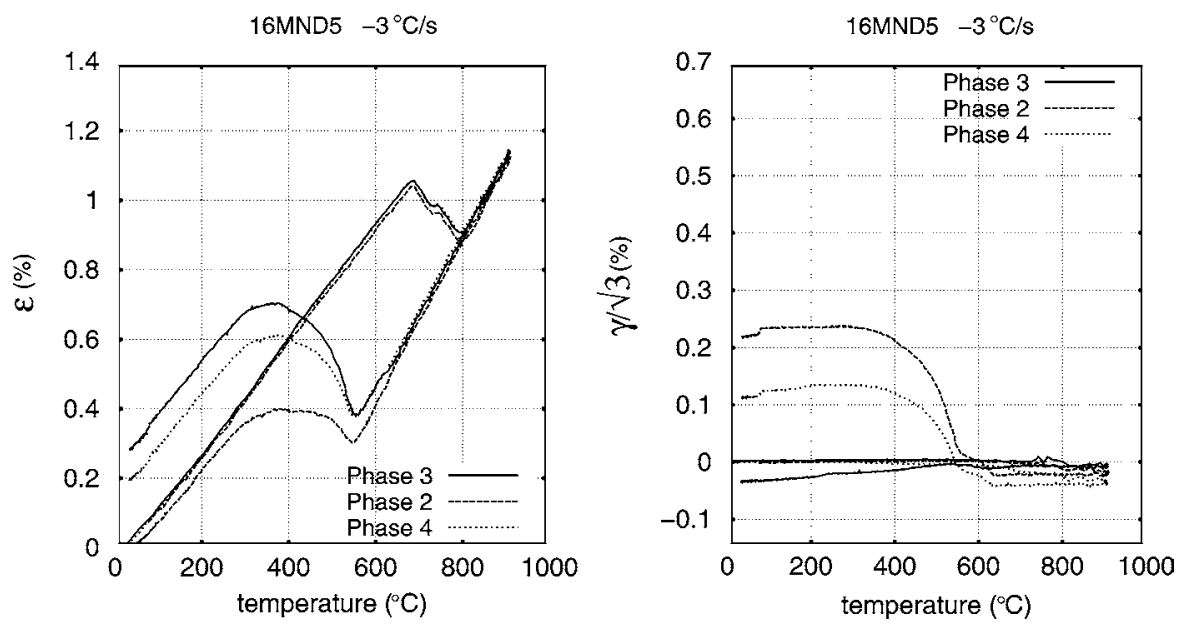

Fig. 16. Evolutions of total axial strain $\varepsilon$ and shear strain $\gamma$ during phases 2, 3 and 4 of test 1 .

strain remains constantly zero during heating. Finally, the small slope breaks visible around $100{ }^{\circ} \mathrm{C}$ correspond to the release of the mechanical loads.

We must now extract from these curves the transformation plastic strains. For this purpose, we consider the following decomposition of the total strain rate:

$$
\underline{\underline{\varepsilon}}=\underline{\underline{\varepsilon}}^{\mathrm{e}}+\underline{\underline{\dot{\varepsilon}}}^{\mathrm{th}}+\underline{\underline{\varepsilon}}^{\mathrm{pt}}+\underline{\underline{\dot{\varepsilon}}}^{\mathrm{vp}}
$$

where $\underline{\dot{\varepsilon}}^{\mathrm{e}}$ is the elastic strain rate

$\underline{\bar{\varepsilon}}^{\text {th }}$ is the thermal strain rate

$\underline{\overline{\dot{\varepsilon}}}^{\mathrm{pt}}$ is the transformation plastic strain rate

$\underline{\overline{\dot{\varepsilon}}}^{\mathrm{vp}}$ is the viscoplastic strain rate.

Furthermore,

$$
\dot{\varepsilon}^{e}=\frac{\dot{\sigma}}{E(T)} \quad \dot{\gamma}^{\mathrm{e}}=\frac{2(1+v)}{E(T)} \dot{\tau}
$$

where $E(T)$ and $v$ are the Young's modulus and the Poisson ratio, respectively. $E(T)$ is considered identical for each phase and given by the following equation (Martinez, 1999):

$$
E(T)=2,08.10^{5}-1,90.10^{2} T+1,19 T^{2}-2,82.10^{-3} T^{3}+1,66.10^{-6} T^{4}
$$

where $E(T)$ and $T$ are given in $\mathrm{MPa}$ and ${ }^{\circ} \mathrm{C}$.

The function $\underline{\underline{\varepsilon}}^{\text {th }}(T)$ is known from the free dilatometry test. $\underline{\underline{\varepsilon}}^{\mathrm{vp}}(T)$ corresponds to the classical viscoplastic strain which develops when a stress is applied. One can consider this quantity negligible since the stress levels applied during the tests are low. Let us recall that the maximum equivalent applied stress is $60 \mathrm{MPa}$, whereas the 
conventional yield stress of austenite at $600{ }^{\circ} \mathrm{C}$ is $100 \mathrm{MPa}$. If we compute the viscoplastic strain due to an applied stress of $60 \mathrm{MPa}$ during $100 \mathrm{~s}$ at $600{ }^{\circ} \mathrm{C}$ we obtain $\varepsilon^{\mathrm{vp}}=8 \times 10^{-6}$. This strain is negligible with respect to the other strains. Therefore, we can determine the axial and shear transformation plastic strains by the following expressions:

$$
\begin{gathered}
\varepsilon^{\mathrm{pt}}=\varepsilon-\varepsilon^{\mathrm{e}}-\varepsilon^{\mathrm{th}} \\
\gamma^{\mathrm{pt}}=\gamma-\gamma^{\mathrm{e}}
\end{gathered}
$$

Thus, still in the case of a bainitic transformation, the transformation plastic strains for the different tests are represented in Figs. 17-19. Qualitatively, we observe that a torque alone causes only a shear plastic strain (Figs. 17a, 18a, 19a), a force alone causes an axial strain (Figs. 17b, 18b, 19b) and a torque plus a force generate axial and shear strains (Figs. 17c, 18c, 19c). Finally, let us observe that the higher the load, the more transformation plasticity develops.

\subsection{Analysis of experimental results}

The analysis of the influence of stress state on transformation plasticity is made in order to validate or invalidate the evolution of the transformation plasticity rate proposed in recent papers (Desalos, 1981; Inoue and Wang, 1985; Leblond et al., 1989). Indeed, for this type of models, the transformation plasticity rate depends on the austenite volume fraction, $z$, the austenite volume fraction rate, $\dot{z}$, and the stress deviator, $\mathbb{S}$ by the following relation:

$$
\underline{\underline{\varepsilon}}^{\mathrm{pt}}=k \cdot f(z) \dot{z} \cdot \underline{\underline{S}}
$$

where $k$ is a material constant, and $f$ is a material function, and

$$
\underline{\underline{S}}=\underline{\underline{\sigma}}-\frac{1}{3} \operatorname{Tr}[\underline{\underline{\sigma}}] \underline{\underline{\underline{ }}}
$$

We can easily integrate Eq. (5) on the phase transformation interval, $\left[t_{0}, t_{1}\right]$,in all cases of considered loadings (Fig. 12). Indeed, the stress state is constant during the phase transformation and for all the tests. So, we can write:

$$
\begin{aligned}
& \int_{t_{0}}^{t_{1}} \dot{\underline{\varepsilon}}^{\mathrm{pt}} \mathrm{d} t=\int_{t_{0}}^{t_{1}} k f(z) \dot{z} \underline{\underline{S}} \mathrm{~d} t=\underline{\underline{S}} \int_{t_{0}}^{t_{1}} k f(z) \dot{z} \mathrm{~d} t \\
& \underline{\dot{\varepsilon}}^{\mathrm{pt}}=\underline{\underline{S}} \int_{t_{0}}^{t_{1}} k f(z) \dot{z} \mathrm{~d} t \\
& \varepsilon_{\mathrm{eq}}^{\mathrm{pt}}=\frac{2}{3} I \sigma_{\mathrm{eq}}
\end{aligned}
$$

where $\varepsilon_{\mathrm{eq}}^{\mathrm{pt}}=\sqrt{\varepsilon^{\mathrm{pt}^{2}}+\frac{\gamma^{\mathrm{pt}^{2}}}{3}}, \sigma_{\mathrm{eq}}=\sqrt{\sigma^{2}+3 \tau^{2}}$ and $I=\int_{t_{0}}^{t_{1}} k f(z) \dot{z} \mathrm{~d} t$. 

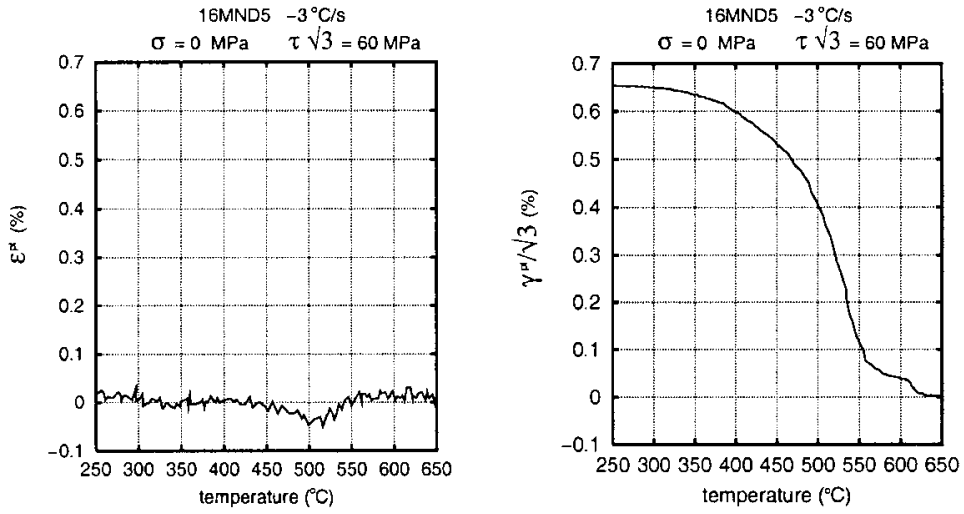

(a) Applied torque
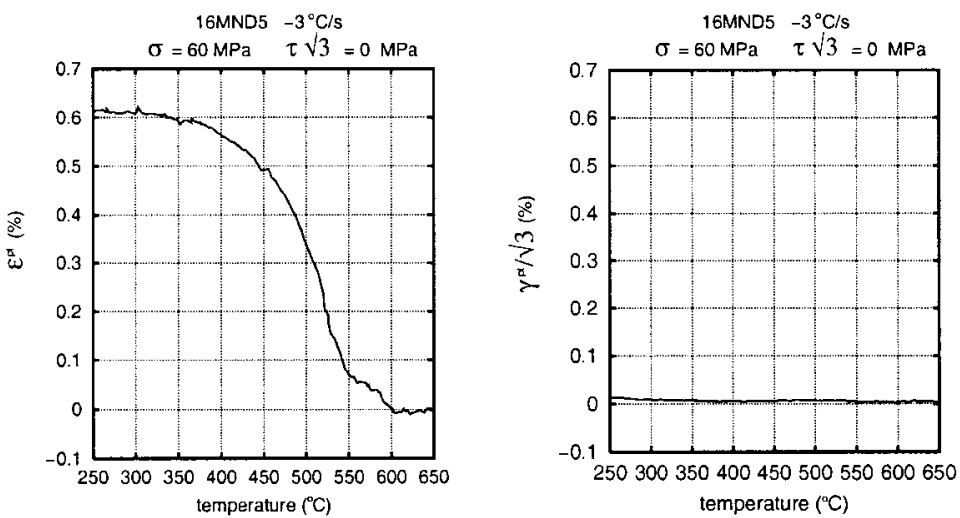

(b) Applied force
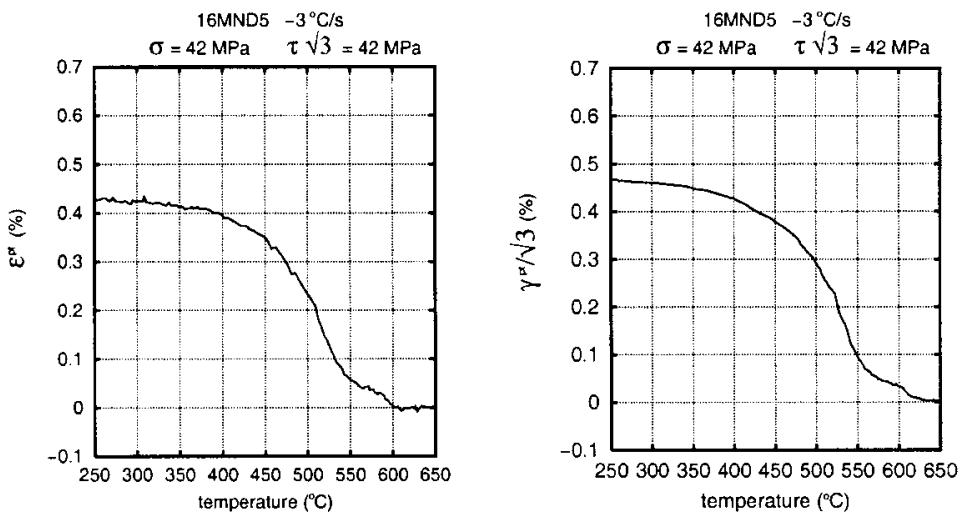

(c) Applied force and torque

Fig. 17. Evolution of transformation plastic strains $\varepsilon^{\mathrm{pt}}$ and $\gamma^{\mathrm{pt}}$ versus temperature for the different stress states at $\sigma_{\mathrm{eq}}=60 \mathrm{MPa}$. 

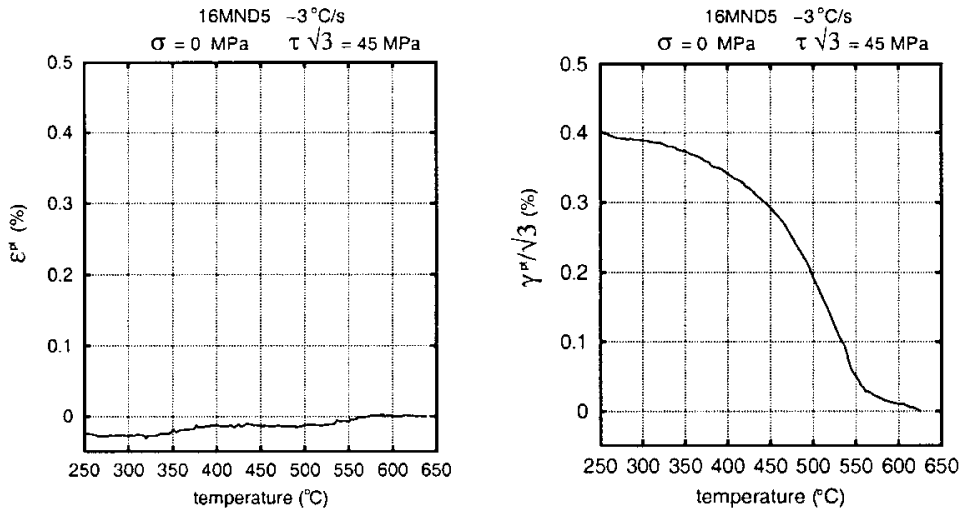

(a) Applied torque
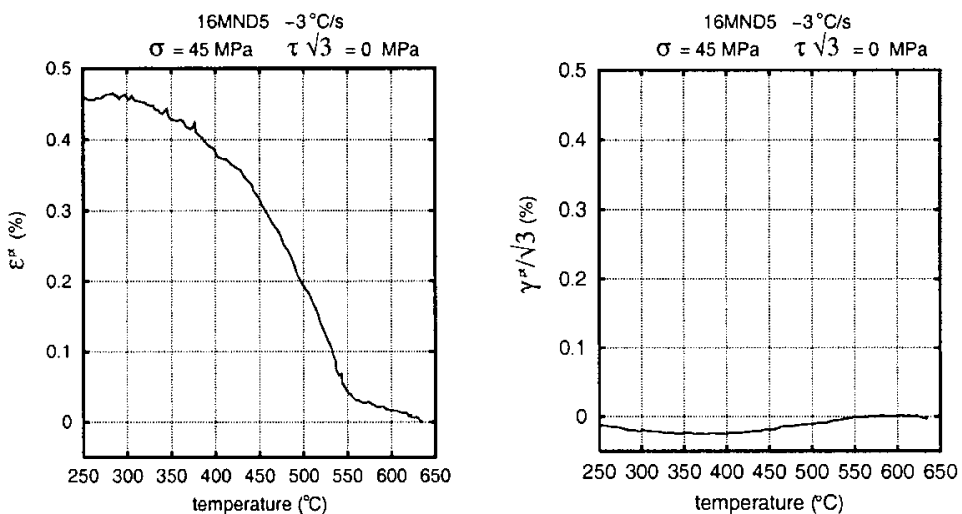

(b) Applied force
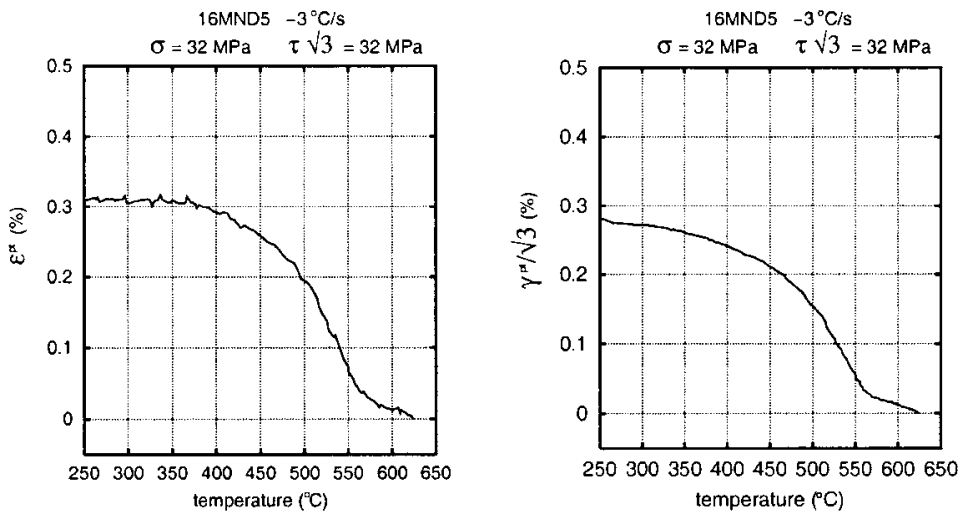

\section{(c) Applied force and torque}

Fig. 18. Evolution of transformation plastic strains $\varepsilon^{\mathrm{pt}}$ and $\gamma^{\mathrm{pt}}$ versus temperature for the different stress states at $\sigma_{\mathrm{eq}}=45 \mathrm{MPa}$. 

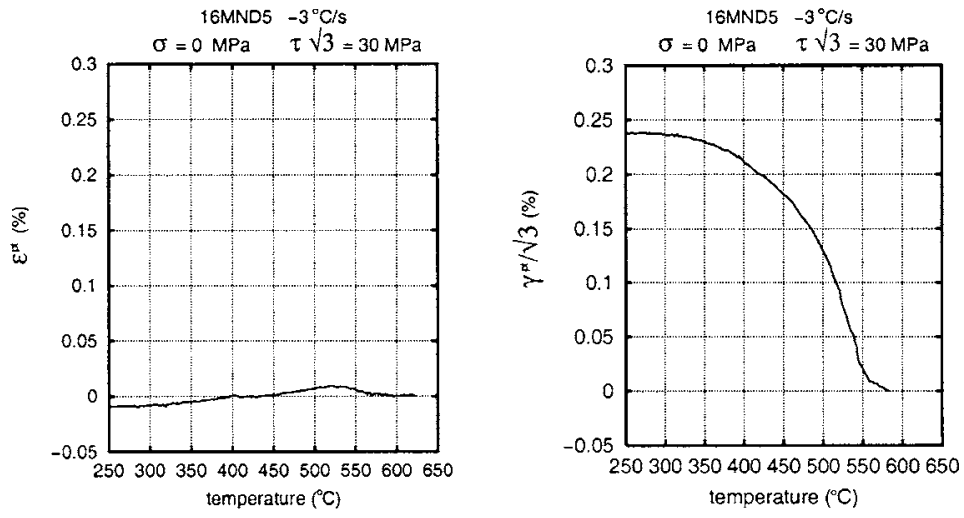

(a) Applied torque
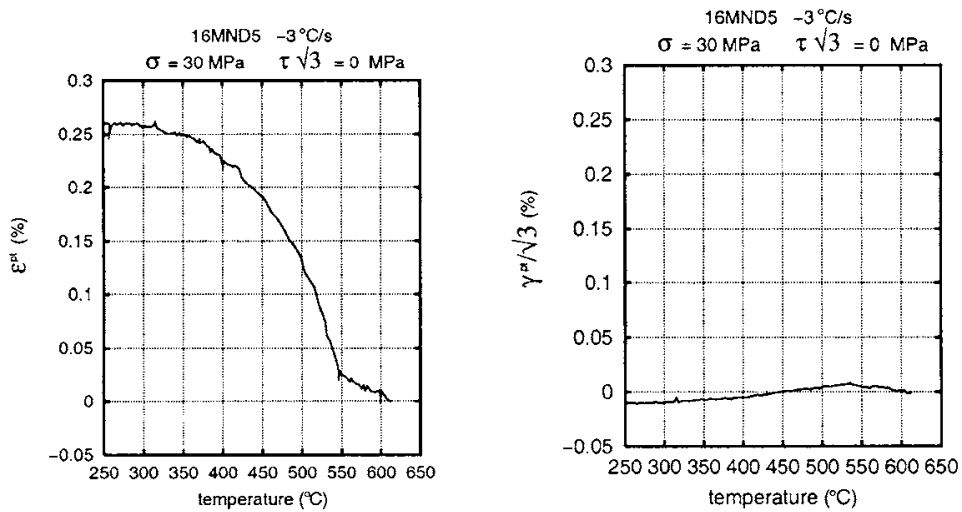

(b) Applied force
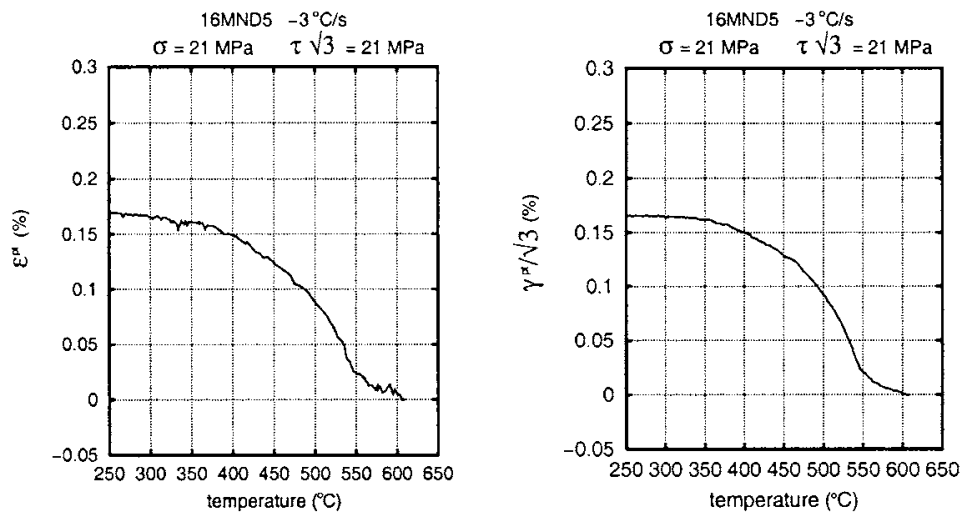

(c) Applied force and torque

Fig. 19. Evolution of transformation plastic strains $\varepsilon^{\mathrm{pt}}$ and $\gamma^{\mathrm{pt}}$ versus temperature for the different stress states at $\sigma_{\mathrm{eq}}=30 \mathrm{MPa}$. 


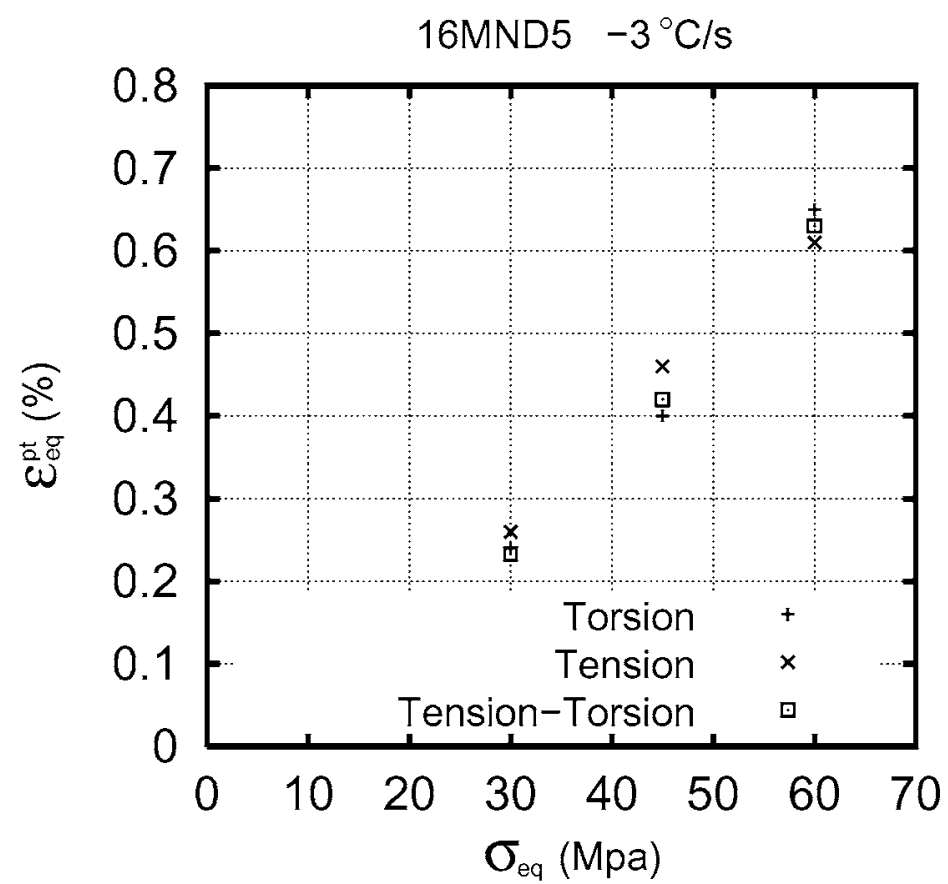

Fig. 20. Plastic strain of the equivalent maximum transformation versus the equivalent von Mises stress.

One can remark in relation (9) that $I$ depends only on the phase transformation considered and does not depend on the stress state. So, for all the loadings considered in our tests, to any level of equivalent stress, $\sigma_{\text {eq }}$, corresponds a level of equivalent plastic transformation strain, $\varepsilon_{\mathrm{eq}}^{\mathrm{pt}}$.

For all the tests presented above, the temperature loading is identical and leads to a bainitic transformation. Then, the integral $I$ is constant for all the tests. So, Fig. 20 shows the equivalent plastic transformation strain level as a function of equivalent stress level. One can observe in Fig. 20 that for all stress level applied in von Mises' sense the equivalent strain levels are identical regardless of the type of mechanical loading. These original experimental results seem to confirm models like Eq. (5), where transformation plasticity strain rate is proportional to the deviatoric stress tensor.

\section{Conclusion}

We have developed an experimental apparatus to apply severe thermomechanical loads on tension-torsion test specimens. This device enables us to reach temperatures of $1200{ }^{\circ} \mathrm{C}$ at a maximum heating rate of $60{ }^{\circ} \mathrm{C} \mathrm{s}^{-1}$. Furthermore, very high cooling rates, on the order of $-30{ }^{\circ} \mathrm{C} \mathrm{s}^{-1}$, can be applied. Therefore, we are able, with such a device, to obtain all possible metallurgical transformations of low carbon steels, from ferritic-pearlitic transformations for the lowest cooling rates to martensitic 
transformations obtained in high-speed cooling. In addition to temperature control, all in-plane stress states $(\sigma, \tau)$, constant with time or not, can be achieved. A first series of tests was conducted. The first series of tests presented here seem to validate classical Eq. (5) describing transformation plasticity in the case of considered loadings in the present paper. The model has to be tested for martensitic transformation as well as austenitic transformation (in case of heating). As a second step, it will be useful to compare these models to multiaxial nonproportional load cases.

\section{Acknowledgements}

Our deepest thanks go to CEA/DMT which sponsored this work, provided the material and constantly supported our research.

\section{References}

Abrassart, F., 1972. Influences des transformations martensitiques sur les propriétés des alliages du système $\mathrm{Fe}-\mathrm{Ni}-\mathrm{Cr}-\mathrm{C}$. $\mathrm{PhD}$ thesis, Université de Nancy.

Applications de l'électricité, D., 1982. Le Chauffage par Induction, Conception et Applications Industrielles. Technical report, EDF.

Cherkaoui, M., Berveiller, M., 2000. Micromechanical modeling of the martensitic transformation induced plasticity in steels. Smart Mater. Struct. 9, 592-603.

Denis, S., Sjöström, S., Simon, A., 1987. Coupled temperature, stress, phase transformation calculation model, numerical illustration of the internal stresses evolution during cooling of a eutectoide carbon steel cylinder. Metall. Trans. 18A, 1203-1212.

Desalos, Y., 1981. Comportement Mécanique et Dilatométrique de l'Auténite Métastable de l'Acier a533. Rapport No 953494 01, IRSID.

Ellis, J., Bartolotta, P., 1997. Adjustable work coil fixture facilitating the use of induction heating in mechanical testing, Multiaxial fatigue and deformation testing techniques. S. Kalluri and P.J. Bonacuse, astm, stp 1280 edition.

Fischer, F., Reisner, G., Werner, E., Tanaka, K., Cailletaud, G., Antretter, T., 2000. A new view on transformation induced plasticity (trip). Int. J. Plasticity 16, 723-748.

Gautier, E., Denis, S., Liebaut, C., Sjöström, S., 1994. Mechanical behaviour of fe-c alloy during phase transformations. Jal. Ph. IV C3 (4), 279-284.

Greenwood, G., Johnson, R., 1965. The deformation of metals under small stresses during phase transformations. Proc. R. Soc. 283, 403-422.

Hamata, N., Billardon, R., Marquis, D., Cheikh, A. B., 1991. In: Desai, C.S. et al. (Eds.), A Model for Nodular Graphite Cast Iron Coupling Anisothermal Elasto-viscoplasticity and Phase Transformation, Constitutive Laws for Engineering Materials. ASME Press.

Inoue, T., Wang, Z., 1985. Coupling between stress, temperature, and metallic structures during processes involving phases transformations. Mater. Sci. Technol. 1, 845-850.

Leblond, J., Devaux, J., Devaux, J., 1989. Mathematical modelling of trans-formation plasticity in steel i. case of ideal-plastic phases. Int. J. Plasticity 5, 551-572.

Magee, C., 1966. Transformation Kinetics, Microplasticity and Aging of Martensite in FE31Ni. Thèse, Carnegie Inst. Technologie, Pittsburg PA.

Martinez, M., 1999. Jonction 16MND5-INCONEL 690-316LN par Soudage Diffusion Elaboration et Calcul des Contraintes résiduelles de procédé. pHD thesis, ENSMP.

Taleb, L., Cavallo, N., Waekael, F., 2000. Experimental analysis of transformation plasticity. Int. J. Plasticity 16, 1-20.

Videau, J., Cailletaud, G., Pineau, A., 1996. Experimental study of the transformation-induced plasticity in a cr-ni-mo-al-ti steel. J. de Ph. 6, 465-474. 